Research Article

\title{
Flow Enhancement of Mineral Pastes to Increase Water Recovery in Tailings: A Matlab-Based Imaging Processing Tool
}

\author{
S. L. Mondaca, ${ }^{1}$ C. A. Leiva $\mathbb{D}^{1},{ }^{1}$ C. A. Acuña, ${ }^{2}$ and E. A. Serey ${ }^{1}$ \\ ${ }^{1}$ Department of Chemical Engineering, Universidad Católica del Norte, 1270709 Antofagasta, Chile \\ ${ }^{2}$ Department of Chemical and Environmental Engineering, Universidad Técnica Federico Santa María, \\ 2390123 Valparaíso, Chile \\ Correspondence should be addressed to C. A. Leiva; cleiva01@ucn.cl
}

Received 8 January 2020; Revised 29 April 2020; Accepted 11 May 2020; Published 26 May 2020

Academic Editor: Francisco J. Alcalá

Copyright (c) 2020 S. L. Mondaca et al. This is an open access article distributed under the Creative Commons Attribution License, which permits unrestricted use, distribution, and reproduction in any medium, provided the original work is properly cited.

\begin{abstract}
The rate of growth of mining copper industry in Chile requires higher consumption of water, which is a resource limited in quality and quantity and a major point of concern in present times. In addition, the efficient use of water is restricted due to high levels of evaporation (10 to $15\left(1 / \mathrm{m}^{2}\right)$ per day), in particular at the north highland mining sites (Chile). On the contrary, the final disposal of tailings is mainly on pond, which loses water by evaporation and in some cases by percolation. An alternative are the paste thickeners, which generate stable paste (70\% solids), reducing evaporation and percolation and therefore reducing water make up. Water is a resource with more demand as the industries are expanding, making the water recovery processes more of a necessity than a simple upgrade in efficiency. This technology was developed in Canada (early 80s) and it has widely been used in Australia (arid zones with similar weather conditions to Chile), although few plants are using this technology. The tendency in the near future is to move from open ponds to paste thickeners. One of the examples of this is Minera El Tesoro. This scenario requires developing technical capacity in both paste flow characterization and rheology modifiers (fluidity enhancer) in order to make possible the final disposal of this paste. In this context, a new technique is introduced and experimental results of fluidity modifiers are discussed. This study describes how water content affects the flow behavior and depositional geometry of tailings and silica flour pastes. The depositional angle determined from the flume tests, and the yield stresses is determined from slump test and a rheological model. Both techniques incorporate digital video and image analysis. The results indicate that the new technique can be incorporated in order to determine the proper solid content and modifiers to a given fluidity requirement. In addition, the experimental results showed that the $\mathrm{pH}$ controls strongly the fluid paste behavior.
\end{abstract}

\section{Introduction}

The growth rate of the copper mining industry in Chile requires a greater water consumption, a resource with limited availability whose industrial use is a major concern nowadays $[1,2]$. The recovery of water from thickened tailings in mining results in an important benefit economically speaking, although it gets more difficult to dewater tailings if they have fine particles [3].

In addition, the efficient use of water is restricted due to the high levels of evaporation (10 to $15\left(1 / \mathrm{m}^{2}\right)$ per day) [4], particularly on the sites of the mines located in the northern highlands. The use of paste thickeners for water recovery proves to be a very efficient method to prevent water loses in tailings depositions, taking into account the large volume of water lost to evaporation [5].

In the case of waste materials from the flotation process (tailings), they range between $95-98 \%$ [4] by weight of the treated material, which are disposed in tailings dams in pulp form. Its transport is carried out by pipeline with an approximate solids consistency from $40 \%$ to $60 \%$ [4], to prevent the line from getting stuck and to reduce energy consumption during pumping [6]. Given the large volumes of water handled, part of the water is recovered and recirculated to the flotation stage after the solids are settled in the tailings dam. Alternatively, another option to increase the 
water recovery is to thicken the pulp up to $75 \%$, which is then available as a paste, using new technologies, such as thickened tailings disposal (TTD) [7].

The use of new technologies or "Paste Technology" [8] was firstly utilized at the end of the year 1980 [9] and since then it is used to describe the disposal of paste with a high content of fines (silt or clay) and low contents of water in the filling material that can be transported through distribution pipes (10 to $20 \mathrm{~cm}$ in diameter). This "Paste," unlike the filling sludge, does not separate in different phases (solid and liquid) at low speeds in transport pipes. The transport of pastes by pipes requires that enough fine material $(20[\mu \mathrm{m}]$ or less) is contained within the mixture so that the lubrication of the pipe walls creates a state of piston flow. Tailings can be transported for filling uses or, given their high surface, in a tailings management facility.

This natural abundance of fine-grained materials is not exclusive in tailings from mines, and it is also common in waste streams from other industries, which are transported as pastes by pipes and are located in places without producing particle segregation. The potential use of paste technology has expanded in recent years $[3,5]$ because it is recognized as a low-cost, environmentally superior technology with technologically controllable methods for transporting and allows commercializing certain waste streams from materials with a low water content and high density. An example of the economic impact of implementing this technology is the comparison made by JRI Engineering, for the Codelco Norte Division, where it is concluded that paste technology yields up to $15 \%$ savings, compared to the conventional alternative [10]. Rheology control in pastes has various possible effects or consequences. The nature of the paste facilitates the mixing of one or more secondary waste materials, which allows all waste materials to be transported by pipes. The increase in density decreases the ratio of supernatant/treatment, reduces mobilization of contaminants, hydraulic conductivity, and oxygen/ reactivity of water through encapsulation within the paste matrix [8]. Due to these effects, among others [11-15], it is proposed to set up a laboratory with characterization tests, which determines yield stress and angle of repose in pastes. Additionally, taking into account that the use of a more automatic control system allows increasing the efficiency of the procedures in different areas [16-19], it is proposed to develop a technique based on digital video and image processing using Toolbox Image ProcessingMatlab, system widely utilized to facilitate the analysis of data for different types of processes [20-23].

The results allow to quantitatively evaluate the effect of $\mathrm{pH}$ on the fluidility and angle of repose in the test pastes. With respect to the additive used, sulfuric acid acts as a dispersant increasing the fluidity and decreasing the angle of repose in the pastes; in the case of the technique implemented, it is concluded that this allows to analyze the dynamic behavior and the profile of the paste throughout time, making the rheological study in pastes possible.

\section{Materials and Methodology}

2.1. Designs of Slump Test Equipment. Slump and flume test equipment are designed and constructed based on the criteria and methodologies developed in previous investigations $[24,25]$. In the slump test, the height of the paste is measured over time, to determine the corresponding yield stress. Analysis models have been developed to relate the slump value to the value of the corresponding yield stress and to predict the slump behavior of the material. Slump models are derived from the first principles with the model variables expressed in dimensionless form. Thus, the slump is not an empirical model and provides the independent matter with a unique relationship between the yield stress and the slump height.

The slump test, which is usually performed on conical geometries, was adapted to a cylindrical geometry for the alumina industry. This is due to the fact that there is a relationship between the slump height and the flow behavior in the bauxite waste, correlation which is adaptable to the case of copper mining pastes due to similar physical characteristics.

Figure 1 shows the comparison between the cone and cylinder models, both the theoretical results and those obtained in the laboratory. It can be clearly seen that the experimental results when using the cylinder model are quite close to the theoretical model, unlike the cone model that shows a significant deviation compared to the empirical results. Taking this information into account, it is decided to use the cylindrical model, as it predicts more precisely the yield stress in pastes.

The results are expressed in terms of dimensionless variables to allow the generalization of the slump test model and are defined as follows:

$$
\text { Cylinders }{ }^{\prime}=1-2 \tau_{y}^{\prime}\left[1-\ln \left(2 \tau_{y}^{\prime}\right)\right] \text {, }
$$

where $\tau_{y}^{\prime}=\tau_{y} / \rho g H$ dimensionless creep limit. $s^{\prime}=s / H$ dimensionless drop height. $h_{0}^{\prime}=h_{0} / H$ dimensionless paste height without deformation. $h_{1}^{\prime}=h_{1} / H$ dimensionless deformed paste height.

Figure 2 determines that, for the cylinder test, the diameter that obtained a lower value of deviation $(<10 \%$ between the theoretical-experimental curves) was the geometry with diameter of $200 \mathrm{~mm}$, with a value in the diameter-height ratio of 1 . From this it is concluded that the diameter of the cylinder to be used in the experimentation will be $200 \mathrm{~mm}$.

To determine the yield stress in the slump test, a series of assumptions are used, which are analyzed in more detail in reference [24]:

(a) It is assumed that no deformation of the paste occurs in the removal of the cylinder in the drop test.

(b) Only the effort acts on the test paste and is assumed as a vertical effort associated with the weight of the paste itself.

(c) The test paste is supposed to behave like an elastic solid so that the maximum shear stress that can be 


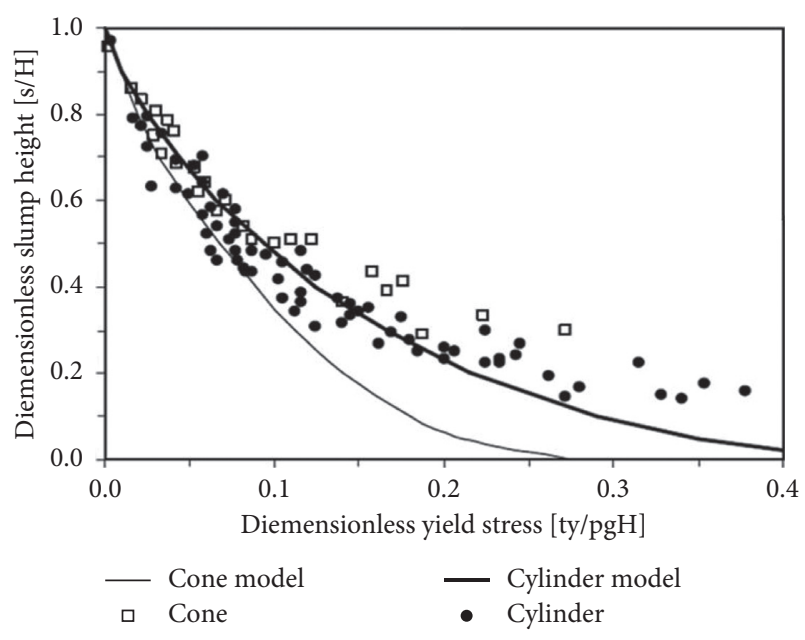

FIgURE 1: Theoretical-experimental comparison of cylinder and cone models, figure adapted from reference [24].

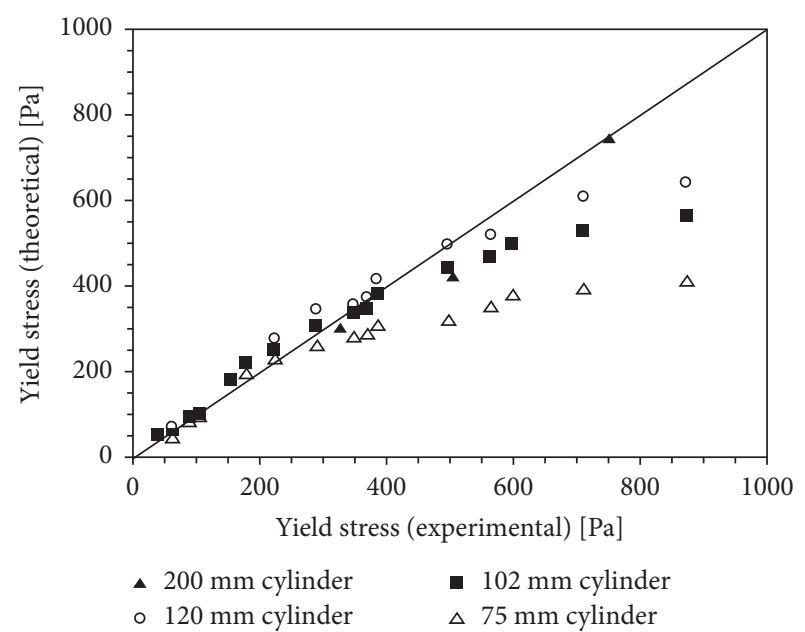

FIgURE 2: Relationship between the diameter of the cylinder and the theoretical prediction of the yield stress, figure adapted from reference [24].

applied to a body when a "P" pressure is applied in a normal direction which is equal to half the pressure.

(d) At some point along the height of the cylinder, the test paste experiences a tension that is greater than the creep limit and the paste flows until the tension is again reduced to the creep limit and remains motionless.

(e) In the process of falling, it is assumed that the interface layer between the paste that exhibits an elastic and inelastic behavior is a horizontal surface that moves down as the test paste flows below it.

(f) The flow occurs until the cross section increases the area so that the effort required to support the weight of the paste above any given plane is reduced to the creep limit. Thus, the product of the tension and the cross section is proportional to the weight of the paste on the plane.
The manufacturing material is acrylic to ensure a homogeneous and complete filling of the geometry. To achieve good video quality, the geometry must have a contrasting base and background surface, in addition to good lighting.

2.2. Designs of Flume Test Equipment. The flume test, used to determine the angle of repose in mineral pastes [25], was developed considering the characteristics of the paste under study. To determine the angle of repose of the paste, equation (2) is used. A schematic diagram is presented in Figure 3.

$$
\theta_{1}=\tan ^{-1}\left(\frac{H_{1}-H_{2}}{L}\right) \text {. }
$$

The equipment is built in acrylic to observe the profile of the paste over time, and the geometry used is rectangular and similar to a flume with a feeding chamber with a sliding door. The representation of the equipment is shown in Figure 4 . To achieve good video quality, the geometry must have a contrasting base surface and background lighting.

2.3. Designs of Technique for Video Monitoring of Pastes. For analyzing results and image processing and recording tools, Matlab ${ }^{\circledR}$ Toolbox Image Processing and Free Video to Jpg. Converter software were used. For moving pastes, a digital video camera with $720 \times 480$ video resolution and color depth of 8 bits per pixel ( 256 colors) is used. The videos are recorded in.wmv format. The videos captured in the camera are edited with the software Camtasia Studio 6 to remove the time slots that are not considered in the image processing.

The original set of captured images (video) is separated into 30 frames per second with Free Video to JPG Converter software. These individual images or frames correspond to a series of points (pixels) capable of storing a color intensity ranging from 0 to 255, using the RGB color model (red, green, and blue); thus, the extensive combination of intensities that each pixel can store is the product of the mixture of primary colors at different intensities, with white being a mixture of maximum intensity $(256,256,256)$ and black a combination of minimum intensity $(0,0,0)$.

From the original image that can be seen in Figure 5, the black and white image shown in Figure 6 is extracted, which allows defining the contour surface and making measurements in the tests. In addition, Toolbox Image Processing allows defining the contour surface of the test in white or black so that from now on the combination of black test surface will be used for the results images.

When working with the RGB color model and using the image processing software tools contained in Matlab's Toolbox Image Processing, it is possible to separate only one color intensity in the frame (red, green, or blue), depending on the contrast surface used in the experience and that better reflects the contour surface for a treatment of the image in binary colors (white or black).

2.4. Description of Operational Parameters and Procedures. Powdered quartz is used, with an approximate granulometry of $100 \%$ under 400 Tyler meshes $(<33 \mathrm{~mm})$. The selection of 


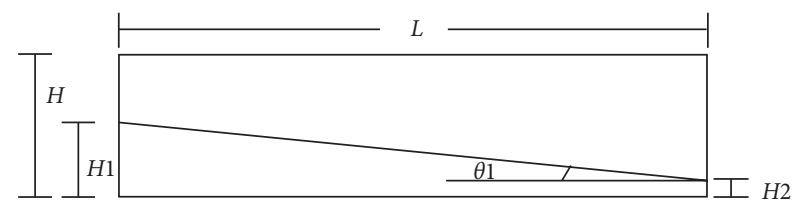

FIgURE 3: Relation schematic diagram of the flume test, where $\theta_{1}=$ angle of repose, $H=$ Initial height $(\mathrm{cm}), H_{1}=$ highest height of the paste $(\mathrm{cm}), H_{2}=$ lowest height of the paste $(\mathrm{cm})$, and $L=$ travel length $(\mathrm{cm})$.

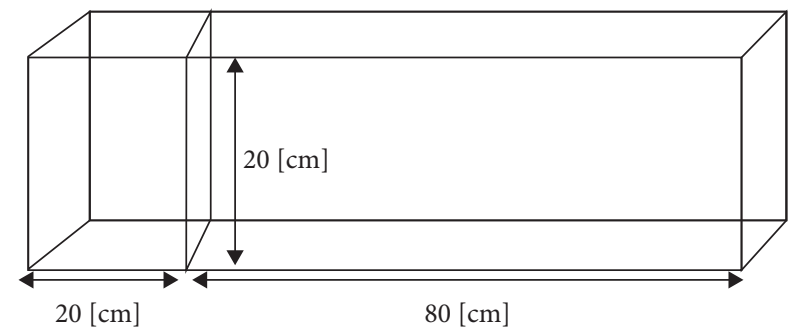

Figure 4: Geometrical characteristics for the flume test.

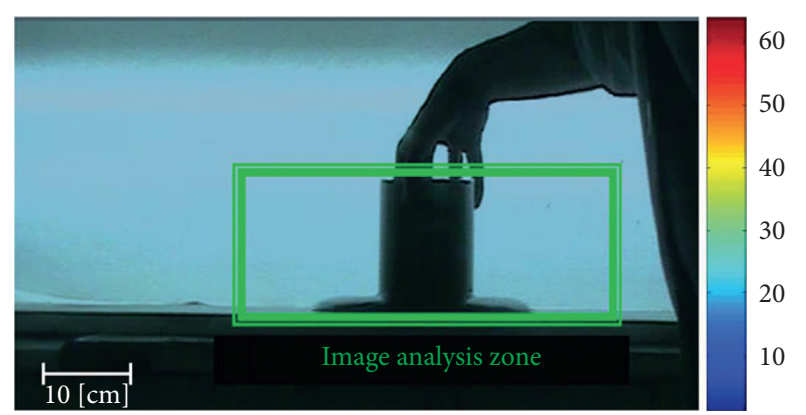

FIGURE 5: Example of the original image of pastes in movement.

the reagents used in the experimentation is based on the effect produced by a polymer and a $\mathrm{pH}$ modifier on the paste, considering quantifying the effect that these additives produce on the pastes at different concentrations of solids, the polymer in $75 \%$ solids and the $\mathrm{pH}$ modifier in $72 \%$ solids. In the case of the polymer, $1 \mathrm{ppm}$ of a polyacrylamide was used with a cationic derivative of acrylic acid, Clarisol, and in the case of the $\mathrm{pH}$ modifier, $1 \mathrm{ppm}$ of sulfuric acid was used.

For the slump test of $70 \%$ solids by weight, the test paste is prepared without adding sulfuric acid, the video camera is installed and configured, and the $\mathrm{pH}$ is measured. Then, the recording begins and the paste is emptied into the geometry of the cylinder. If the paste contains a large quantity of solids, the filling is done in two steps with compaction of the paste to eliminate the dead zones; otherwise, the filling is performed in only one step. Once the entire surface of the geometry is completely filled, the cylinder is lifted, the paste is allowed to flow and the recording stopped in the stationary state of the paste. The paste is then collected and concentrated sulfuric acid (98\%) is added in a ratio of $0.0018 \mathrm{~g}$ of sulfuric acid/ton of dry solid, the $\mathrm{pH}$ is measured, and the same specifications described in the first paragraph of Section2.3 are followed from the paragraph where the recording begins. The experiences are repeated twice and one video is selected for image processing.

In the case of the slump test for the paste of $75 \%$ solids by weight, the paste is prepared without adding cationic polymer, Clarisol; then, the same procedure for the paste with $70 \%$ solids is followed and only the additive used as a rheology modifier changes, using a cationic polyacrylamide concentrated at $10 \% \mathrm{w} / \mathrm{w}$ at a ratio of $0.001 \mathrm{~g}$ of Clarisol/ton dry solid.

In the case of the flume test for $75 \%$ solids by weight, the paste is prepared without adding flocculant, Clarisol; then, the same procedure for the paste with $70 \%$ solids is followed and only the additive used as a rheology modifier is changed, this time using a concentrated cationic polyacrylamide at $10 \% \mathrm{w} / \mathrm{w}$ in a ratio of $0.001 \mathrm{~g}$ of Clarisol/ton dry solid.

The characteristics that the video camera must fulfill are to remain in a fixed position, parallel to the test plane, and at a distance $(L)$ that covers the entire surface of the geometry. In addition, it must have manual brightness adjustment so that there are no automatic adjustments during video recording and image recording quality must be $720 \times 480$ pixels.

\section{Results and Discussion}

3.1. Effect of Sulfuric Acid with $70 \%$ Solid in Slump Test. The image capture was made in time intervals of $1 / 30 \mathrm{~s}$ without sulfuric acid, with a total duration of $1.97 \mathrm{~s}$. The final ratio between the width of the cylinder and the spread of the paste was 2.76. With the use of $0.0018 \mathrm{~g}$ of sulfuric acid/ton dry solid and with a total duration of $1.97 \mathrm{~s}$, the final ratio between the width of the cylinder and the spread of the sludge was 3.26.

When measuring the spread length of the paste with and without the addition of sulfuric acid, it can be observed that a change in the spread velocity of the paste occurs in both tests, being higher in the case with sulfuric acid as presented in Tables 1 and 2 and Figure 7. The graph shows that the addition of acid achieves higher spread velocities at the beginning of the test and that at the end of both tests the velocities obtained were similar.

\subsection{Effect of Sulfuric Acid with $70 \%$ Solid in Flume Test.} For the first case without the use of sulfuric acid, the image capture was made at $1 / 30 \mathrm{~s}$ time intervals with a total duration of $5.37 \mathrm{~s}$, for which the angle of repose of the paste decreases in $2.3^{\circ}$. For the test with $0.0018 \mathrm{~g}$ of sulfuric acid/ ton dry solid, the image capture was performed in time intervals $1 / 30 \mathrm{~s}$, with a total duration of $1.97 \mathrm{~s}$ the angle of repose of the paste decreases $3.47^{\circ}$.

When measuring the length and height of the spread of the paste with and without the addition of sulfuric acid, the angle of repose is calculated to quantify the variation of the angle of repose in time, showing lower values in the paste sequence $70 \%$ solid with acid sulfuric. This parameter on an industrial scale means that the solid with these 


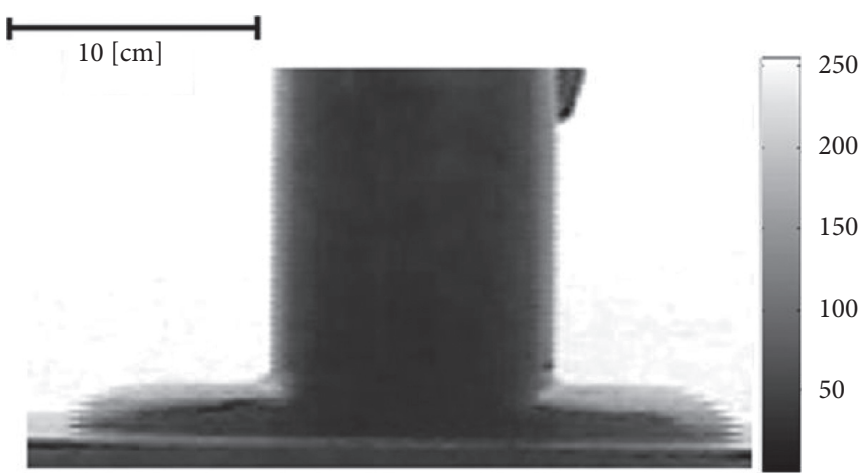

(a)

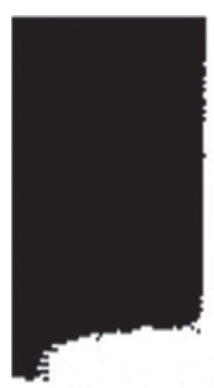

(b)

FIGURE 6: Example of binary image: (a) original image and (b) binary image.

TABLE 1: Slump test without sulfuric acid, cylinder.

\begin{tabular}{lccccc}
\hline Length $(\mathrm{cm})$ & Real length $(\mathrm{cm})$ & Ratio $L / C$ & Time $(\mathrm{s})$ & Real length increase & Spread velocity $(\mathrm{cm} / \mathrm{s})$ \\
\hline 4.74 & 20.00 & 1.00 & 0 & 0 & 0 \\
5.50 & 23.21 & 1.16 & 0.13 & 3.21 & 24.05 \\
7.30 & 30.80 & 1.54 & 0.30 & 10.80 & 36.01 \\
8.15 & 34.39 & 1.72 & 0.47 & 14.39 & 30.83 \\
9.40 & 39.66 & 1.98 & 0.63 & 22.62 & 31.05 \\
10.10 & 42.62 & 2.13 & 0.80 & 26.33 & 28.27 \\
10.98 & 46.33 & 2.32 & 0.97 & 27.93 & 24.65 \\
11.36 & 47.93 & 2.40 & 1.13 & 29.79 & 22.91 \\
11.80 & 49.79 & 2.49 & 1.30 & 32.32 & 22.04 \\
12.40 & 52.32 & 2.62 & 1.47 & 33.25 & 18.89 \\
12.62 & 53.25 & 2.66 & 1.63 & 34.01 & 17.94 \\
12.80 & 54.01 & 2.70 & 1.80 & 35.27 & \\
13.10 & 55.27 & 2.76 & 1.97 & & \\
\hline
\end{tabular}

TABLE 2: Slump test with sulfuric acid, cylinder.

\begin{tabular}{lccccc}
\hline Length $(\mathrm{cm})$ & Real length $(\mathrm{cm})$ & Ratio $L / C$ & Time $(\mathrm{s})$ & Real length increase & Spread velocity $(\mathrm{cm} / \mathrm{s})$ \\
\hline 4.53 & 20.00 & 1.00 & 0 & 0 & 0 \\
7.28 & 32.14 & 1.61 & 0.13 & 12.14 & 91.06 \\
11.35 & 50.11 & 2.51 & 0.30 & 30.11 & 100.37 \\
12.90 & 56.95 & 2.85 & 0.47 & 36.95 & 79.19 \\
14.15 & 62.47 & 3.12 & 0.63 & 42.47 & 67.06 \\
14.24 & 62.87 & 3.14 & 0.80 & 42.87 & 53.59 \\
14.38 & 63.49 & 3.17 & 0.97 & 43.49 & 44.99 \\
14.62 & 64.55 & 3.23 & 1.13 & 44.55 & 39.31 \\
14.65 & 64.68 & 3.23 & 1.30 & 44.68 & 34.37 \\
14.76 & 65.17 & 3.26 & 1.47 & 45.17 & 30.79 \\
14.76 & 65.17 & 3.26 & 1.63 & 45.17 & 27.65 \\
14.76 & 65.17 & 3.26 & 1.80 & 45.17 & 25.09 \\
14.76 & 65.17 & 3.26 & 1.97 & 45.17 & 22.97 \\
\hline
\end{tabular}

characteristics needs less energy to be transported. Graphically the results are reflected in Figure 8 and the data is in Tables 3 and 4. From Figure 8, it can be seen that the flume test of $70 \%$ solids with the addition of sulfuric acid causes a decrease in the angle of repose of the paste and shorter spread time.
3.3. Effect of Cationic Polymer Clarisol with $75 \%$ Solids in Slump Test. The slump test with 75\% solids does not present variations in height, as shown in Figure 9, which represents the initial, intermediate, and final images of the test at times $0,1.07$ and $1.63 \mathrm{~s}$, respectively. It us worth mentioning that without the addition of cationic polymer; the high 


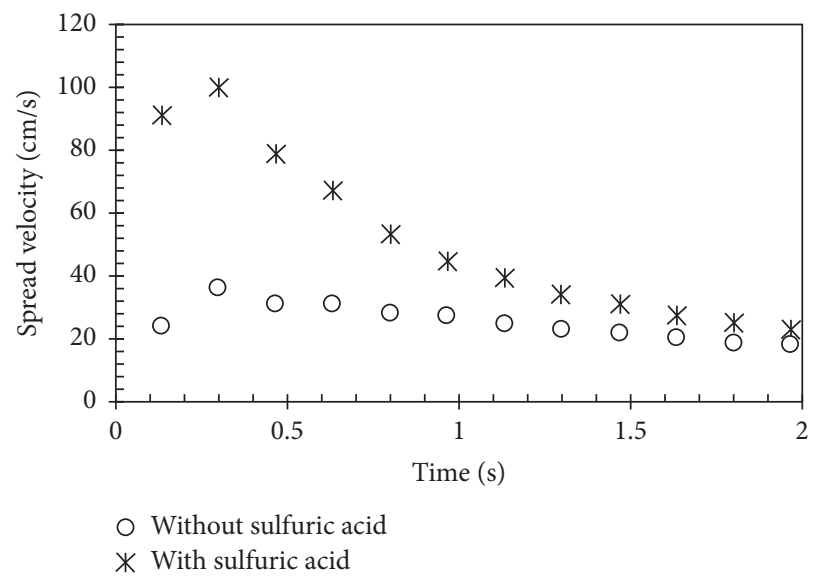

FIgURE 7: Graph of spread velocity vs. time, slump test.

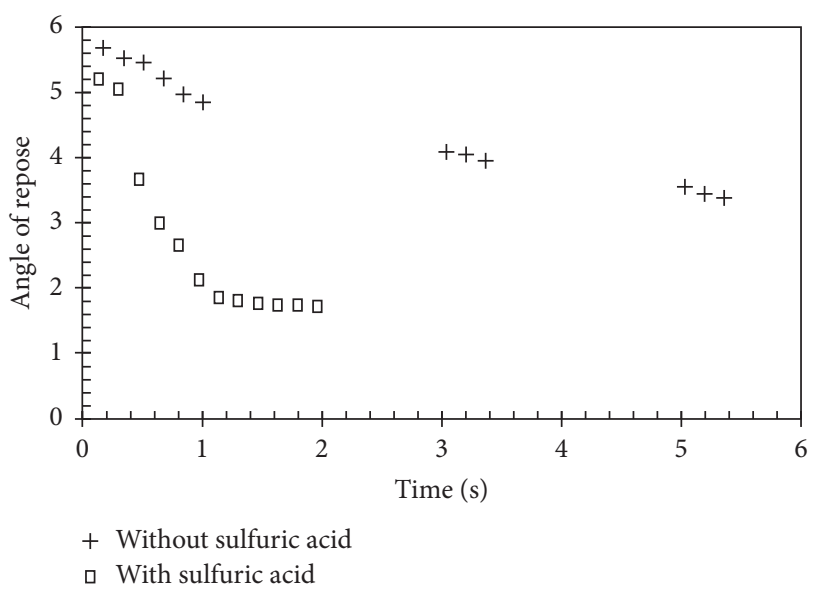

FIGURE 8: Graph of angle of repose vs. time, flume test.

TABLE 3: Flume test without sulfuric acid, cylinder.

\begin{tabular}{lcccc}
\hline Height $(\mathrm{cm})$ & Length $(\mathrm{cm})$ & $\left(H_{1} / L\right)$ & Degrees & Time $(\mathrm{s})$ \\
\hline- & - & - & - & 0.00 \\
0.91 & 9.10 & 0.10 & 5.71 & 0.17 \\
0.88 & 9.10 & 0.10 & 5.52 & 0.33 \\
0.88 & 9.20 & 0.10 & 5.46 & 0.50 \\
0.86 & 9.40 & 0.09 & 5.23 & 0.67 \\
0.83 & 9.50 & 0.09 & 4.99 & 0.83 \\
0.81 & 9.50 & 0.09 & 4.87 & 1.00 \\
0.81 & 11.30 & 0.07 & 4.10 & 3.03 \\
0.81 & 11.45 & 0.07 & 4.05 & 3.20 \\
0.79 & 11.45 & 0.07 & 3.95 & 3.37 \\
0.75 & 12.00 & 0.06 & 3.58 & 5.03 \\
0.73 & 12.05 & 0.06 & 3.47 & 5.20 \\
0.72 & 12.10 & 0.06 & 3.41 & 5.37 \\
\hline
\end{tabular}

concentration of solids would prevent the movement of the test paste. The sequence of images is performed at 1/30 time intervals $\mathrm{s}$ with a total duration of $1.63 \mathrm{~s}$.

When adding Clarisol cationic polymer (0.001 g Clarisol/ ton dry solid), agglomeration of particles is observed. This way, an increase in the apparent viscosity of the paste is
TABle 4: Flume test with sulfuric acid, cylinder.

\begin{tabular}{lcccc}
\hline Height $(\mathrm{cm})$ & Length $(\mathrm{cm})$ & $\left(H_{1} / L\right)$ & Degrees & Time $(\mathrm{s})$ \\
\hline- & - & - & - & 0.00 \\
0.53 & 5.83 & 0.09 & 5.19 & 0.13 \\
0.53 & 6.00 & 0.09 & 5.05 & 0.30 \\
0.55 & 8.57 & 0.06 & 3.67 & 0.47 \\
0.53 & 10.10 & 0.05 & 3.00 & 0.63 \\
0.52 & 11.18 & 0.05 & 2.66 & 0.80 \\
0.46 & 12.40 & 0.04 & 2.12 & 0.97 \\
0.43 & 13.30 & 0.03 & 1.85 & 1.13 \\
0.43 & 13.67 & 0.03 & 1.80 & 1.30 \\
0.42 & 13.67 & 0.03 & 1.76 & 1.47 \\
0.42 & 13.67 & 0.03 & 1.76 & 1.63 \\
0.42 & 13.67 & 0.03 & 1.76 & 1.80 \\
0.41 & 13.67 & 0.03 & 1.72 & 1.97 \\
\hline
\end{tabular}

inferred, as shown in Figure 10, which represents the initial, intermediate, and final image of the test, at time $0,1.43$ and $2.87 \mathrm{~s}$, respectively. The image sequence is performed at 1/30 time intervals (s) with a total duration of $2.87 \mathrm{~s}$.

For both tests, with and without addition of polymer, no changes in the fluidity of the paste occur. Another observation made when comparing the tests is the increase in the time it takes to remove the cylinder during the experiment, from $1.63 \mathrm{~s}$ without additive to $2.87 \mathrm{~s}$ with additive, so the effect that the polymer produces on the test paste would not be favorable for the objectives set out in this investigation.

3.4. Effect of Clarisol Cationic Polymer with 75\% Solids in Flume Test. The flume test with $75 \%$ solids and without added Clarisol does not present variations in height and length. This is reflected in Figure 11, which represents the initial, intermediate, and final image of the test at times 0 , 1.90 , and $3.83 \mathrm{~s}$, respectively. The sequence of images is performed at 1/30 time intervals (s) with a total duration of $3.83 \mathrm{~s}$.

In the case of the flume test with $75 \%$ solids and with $0.001 \mathrm{~g}$ Clarisol/ton dry solid, there are no variations in height and length, which is reflected in Figure 12, which represents the initial, intermediate, and final image of the 


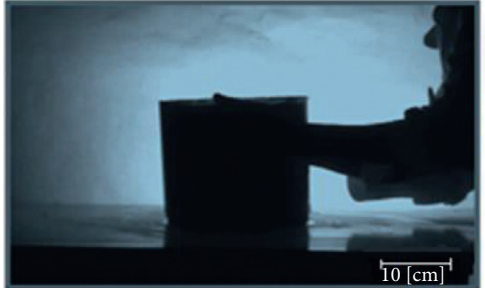

(a)

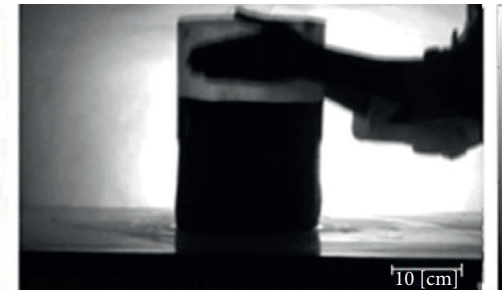

(b)

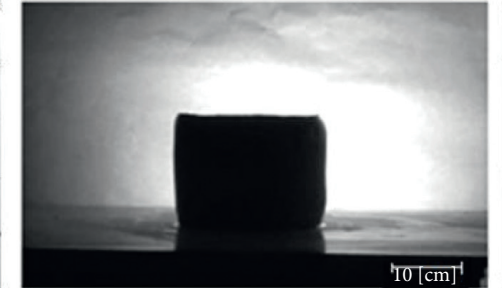

(c)

FIgURE 9: Dynamic monitoring with 75\% solids, slump test without cationic polymer. (a) $t=0 \mathrm{~s}$. (b) $t=1.07 \mathrm{~s}$. (c) $t=1.63 \mathrm{~s}$.

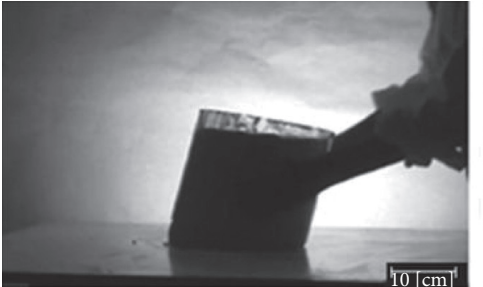

(a)

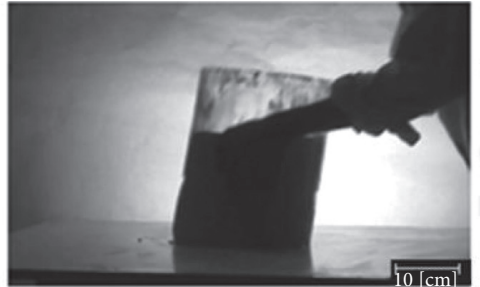

(b)

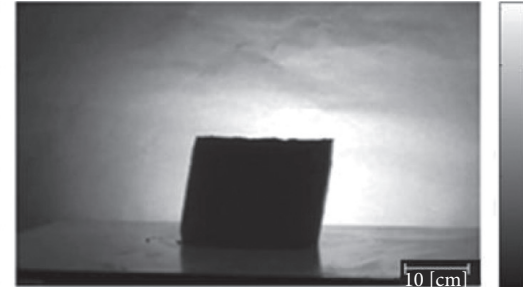

(c)

FIgURE 10: Dynamic monitoring with $75 \%$ solids, slump test with cationic polymer. (a) $t=0 \mathrm{~s}$. (b) $t=1.43 \mathrm{~s}$. (c) $t=2.87 \mathrm{~s}$.

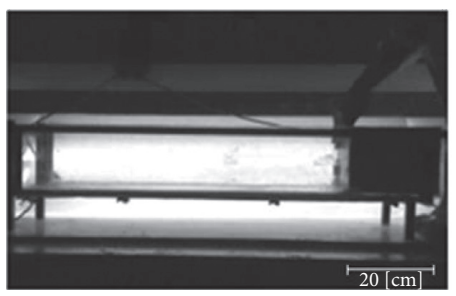

(a)

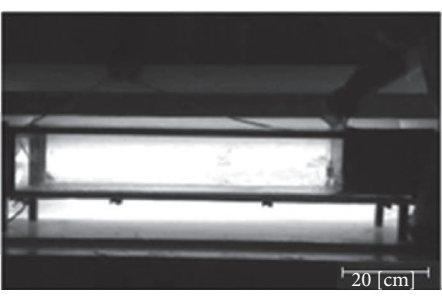

(b)

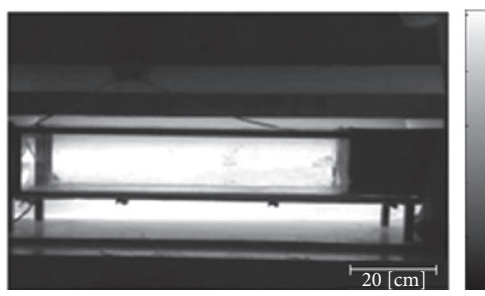

(c)

Figure 11: Dynamic monitoring with $75 \%$ solids, flume test without cationic polymer. (a) $t=0 \mathrm{~s}$. (b) $t=1.9 \mathrm{~s}$. (c) $t=3.83 \mathrm{~s}$.

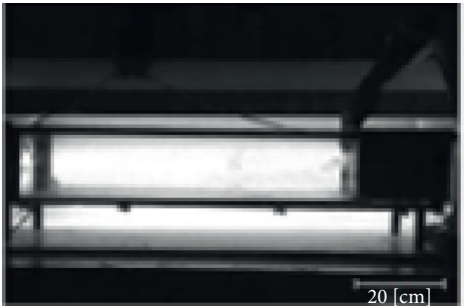

(a)

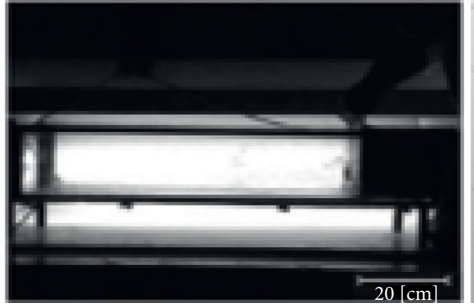

(b)

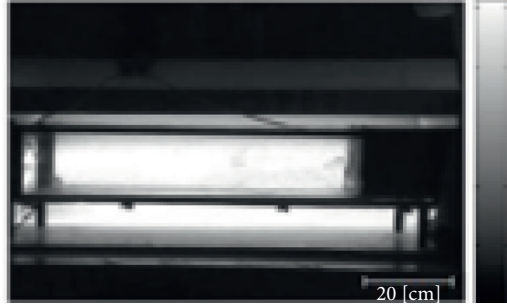

(c)

Figure 12: Dynamic monitoring with $75 \%$ solids, flume test with cationic polymer. (a) $t=0 \mathrm{~s}$. (b) $t=1.9 \mathrm{~s}$. (c) $t=3.83 \mathrm{~s}$.

test at times $0,2.43$ and $4.87 \mathrm{~s}$, respectively. The sequence of images is performed at $1 / 30$ time intervals (s) with a total duration of $4.87 \mathrm{~s}$. In summary, for the flume tests with $75 \%$ solids, with or without addition of cationic polymer Clarisol, no changes in the fluidity of the paste are produced. The time it takes to remove the sliding gate from the flume increases from $3.83 \mathrm{~s}$ without additive to $4.87 \mathrm{~s}$ with additive.

\section{Conclusions}

4.1. Software Utilized. For analyzing results and image processing and recording tools, Matlab ${ }^{\circledR}$ Toolbox Image Processing and Free Video to Jpg.Converter software were used. The videos captured in the camera were edited with the software Camtasia Studio 6 to remove the time slots that are 
not considered in the image processing. In addition, Toolbox Image Processing allows defining the contour surface of the test in white or black so that the combination of black test surface is used for the results images. It us recommended to use the tools and techniques of Matlab ${ }^{\circledR}$ Toolbox Image Processing to analyze, quantify, and compare the effect of the additives over time.

4.2. Novelty and Advantages of the Technique. A technique based on digital video and image processing was developed through the implementation of a laboratory for the characterization of pastes including slump and flume tests. The relevance of implementing image analysis by video should be noted, since it allows to quantify the dynamic behavior in pastes. Regarding the type of rheology modifier used, it is concluded that sulfuric acid meets the objectives, allowing to recover water by increasing fluidity. It is worth mentioning that the use of this technology generates significant savings in water resources compared to current processes, which not only means an economic benefit, but an important step in favor of the sustainable development that is so much needed in these times.

4.3. Limitations. On the contrary, it was not possible to analyze the effect of the polymeric and $\mathrm{pH}$ modifier in tailings pastes, and it was possible to analyze and quantify the effect of a chemical additive as a rheology modifier in pastes of fine granulometry $(<38 \mu \mathrm{m})$ and basic $\mathrm{pH}$.

4.4. Future Work Ahead. It is recommended to modify the dimensions of the flume, specifically the length through which the test paste flows, since the dimensions considered do not allow to evaluate the effect that the addition of more acid produces on the paste. To observe and quantify the behavior of the test pastes throughout time and using image processing, it is recommended to work with percentages of solids comprised between $70 \%$ and $74 \%$ in the cylinder and flume test.

\section{Data Availability}

All data supporting this study are provided as supplementary information accompanying this paper.

\section{Conflicts of Interest}

The authors declare no conflicts of interest.

\section{Authors' Contributions}

Claudio Acuña conceptualized the study; Sofía Mondaca carried out data curation; Claudio Leiva, Claudio Acuña, and Sofía Mondaca carried out formal analysis; Sofía Mondaca carried out investigation; Claudio Acuña and Sofía Mondaca provided the methodology; Claudio Acuña carried out validation; Eduardo Serey wrote the original draft; Claudio Leiva and Eduardo Serey wrote the review and edited the article.

\section{Acknowledgments}

The authors wish to acknowledge the material support provided by the Gabriela Mistral Division, Codelco, financial support provided by Universidad Católica del Norte, and to the student Sofía Mondaca for his contribution with his chemical engineer thesis.

\section{References}

[1] S. Herrera-León, F. A. Lucay, L. A. Cisternas, and A. Kraslawski, "Applying a multi-objective optimization approach in designing water supply systems for mining industries. The case of Chile," Journal of Cleaner Production, vol. 210, pp. 994-1004, 2019.

[2] G. M. Mudd, Mining and Water Resources, Reference Module in Earth Systems and Environmental Sciences, Elsevier, Amsterdam, Netherlands, 2020.

[3] J. Huazhe, W. Shufei, Y. Yixuan, and C. Xinming, "Water recovery improvement by shearing of gravity-thickened tailings for cemented paste backfill," Journal of Cleaner Production, vol. 245, 2020.

[4] COCHILCO, Good Practices and Efficient Use of Water in the Mining Industry, INEH publications, Santiago, Chile, 2008.

[5] J. Johnson and W. Xie, "Paste and thickened tailings water benefits-case studies," in Proceedings of the 20th International Seminar on Paste and Thickened Tailings, A. Wu and R. Jewell, Eds., University of Science and Technology Beijing, Beijing, China, pp. 387-392, 2017.

[6] P. Slatter, "The role of rheology in the pipelining of mineral slurries," Mineral Processing and Extractive Metallurgy Review, vol. 20, pp. 281-300, 1999.

[7] E. I. Robinsky, "Tailings dam failures need not be disasters-the Thickened Tailings Disposal (TTD) system," CIM Bulletin, vol. 92, pp. 140-142, 1999.

[8] D. Landriault, J. M. Johnson, and F. Palkovits, "Thickened tailings and paste technology: the future of industrial waste disposal," SME Annual Meeting: Got Mining-Preprints, vol. 34, pp. 899-908, 2005.

[9] W. Cincilla, D. Landriault, and R. Verburg, "Application of paste technology to surface disposal of mineral wastes," in Proceedings of the Fourth International Conference on Tailings and Mine Waste, Fort Collins, CO, USA, 1997.

[10] J. Rayo, R. Fuentes, and R. Orellana, "Large tailings disposalconventional versus paste," in Proceedings of the Twelfth International Seminar on Paste and Thickened Tailings, R. Jewell, A. B. Fourie, S. Barrera, and J. Wiertz, Eds., Australian Centre for Geomechanics, Perth, Australia, pp. 271278, 2009.

[11] C. Bazin and C. B-Chapleau, "The difficulty associated with measuring slurry rheological properties and linking them to grinding mill performance," International Journal of Mineral Processing, vol. 76, no. 1-2, pp. 93-99, 2005.

[12] S. B. Johnson, G. V. Franks, P. J. Scales, D. V. Boger, and T. W. Healy, "Surface chemistry-rheology relationships in concentrated mineral suspensions," International Journal of Mineral Processing, vol. 58, no. 1-4, pp. 267-304, 2000.

[13] Q. D. Nguyen and D. V. Boger, "Application of rheology to solving tailings disposal problems," International Journal of Mineral Processing, vol. 54, no. 3-4, pp. 217-233, 1998.

[14] L. Spinosa and V. Lotito, "A simple method for evaluating sludge yield stress," Advances in Environmental Research, vol. 7, no. 3, pp. 655-659, 2003. 
[15] D. Wasan, A. Nikolov, and B. Moudgil, "Colloidal dispersions: structure, stability and geometric confinement," Powder Technology, vol. 153, no. 3, pp. 135-141, 2005.

[16] V. Flores, B. Keith, and C. A. Leiva, "Using artificial intelligence techniques to improve the prediction of copper recovery by leaching," Journal of Sensors, vol. 34, 2020.

[17] L. G. Bergh, J. B. Yianatos, and C. A. Leiva, "Fuzzy supervisory control of flotation columns," Minerals Engineering, vol. 11, no. 8, pp. 739-748, 1998.

[18] C. A. Leiva, V. M. Flores, F. Salgado, D. Poblete, and C. Acuña, "Applying softcomputing for copper recovery in leaching process," Science Program, vol. 2017, p. 6, 2017.

[19] C. Leiva, K. Arcos, D. Poblete, E. Serey, C. Torres, and Y. Ghorbani, "Design and evaluation of an expert system in a crushing plant," Minerals, vol. 8, no. 10, p. 469, 2018.

[20] M. A. Molina, C. A. Acuña, and C. A. Leiva, "Characterization of filamentous flocs to predict sedimentation parameters using image analysis," Journal of Sensors, vol. 34, 2020.

[21] B. Klein and M. Pawlik, "Rheology modifiers for mineral suspensions," Mining, Metallurgy \& Exploration, vol. 22, no. 2, pp. 83-88, 2005.

[22] M. Katzer, R. Klimpel, and J. Sewell, "Example of the laboratory characterization of grinding aids in the wet grinding of ores," Minning Engineering, vol. 33, pp. 1471-1476, 1982.

[23] D. B. Braun and M. R. Rosen, "Part 1-practical rheology," in Rheology Modifiers Handbook, pp. 1-69, William Andrew Publishing, Norwich, NY, USA, 1999.

[24] S. Clayton, T. G. Grice, and D. V. Boger, "Analysis of the slump test for on-site yield stress measurement of mineral suspensions," International Journal of Mineral Processing, vol. 70, no. 1-4, pp. 3-21, 2003.

[25] M. Kwak, D. F. James, and K. A. Klein, "Flow behaviour of tailings paste for surface disposal," International Journal of Mineral Processing, vol. 77, no. 3, pp. 139-153, 2005. 